\title{
Testicular cancer risk incidence in perception of young men
}

\author{
Anna Sugajska ${ }^{1}$, Michalina Dudkiewicz ${ }^{2}$, Mateusz Szmit², Robert Jankowski², Robert Ciesak², \\ Magdalena Wołyniec ${ }^{2}$, Klaudia Feruś2 , Katarzyna Bąk², Joanna Kotlińska², Piotr Wojciechowski², \\ Mohammed Mesfer Almalki², Bassam Abdulrahman Bawazir², Konrad Wroński³ \\ Karolina Osowiecka ${ }^{4}$, Monika Rucińska
}

\footnotetext{
${ }^{1}$ Department of Oncology, Faculty of Medicine, Collegium Medicum, University of Warmia and Mazury in Olsztyn, Poland ${ }_{2}^{2}$ Student Scientific Club, Department of Oncology, Faculty of Medicine, Collegium Medicum, University of Warmia and Mazury in Olsztyn, Poland ${ }^{3} \mathrm{General}$ and Colorectal Surgery Clinic, Medical University in Łódź, Poland

${ }^{4}$ Department of Psychology and Health Sociology and Public Health at Collegium Medicum, University of Warmia and Mazury in Olsztyn, Poland
}

Introduction. Testicular cancer is the most frequently occurring malignant tumour in young men. Self-examination of testicles allows for early detection of the disease. The objective of this paper was to evaluate the level of knowledge concerning testicular cancer among young men.

Material and methods. The study was conducted among 296 students of the University of Warmia and Mazury in Olsztyn. Results. The majority of students were never previously interested in the issue of testicular cancer. The students were not able to say at what age this type of cancer usually occurs nor did they know the risk factors or symptoms of the disease. Students of Medicine had much more knowledge about testicular cancer than the students from other fields. $91 \%$ of the examined men declared that doctors never informed them about the risk of developing testicular cancer and the importance of self-examination of the testicles. $72 \%$ of students of faculties other than medical, never searched for any information concerning testicular cancer on their own. Only 29\% of students of all faculties perform self-examination of their testicles. Conclusions. Young man do not have sufficient knowledge concerning testicular cancer and rarely self-examine their testicles. Therefore, it is justified to disseminate more broadly knowledge concerning testicular cancer and to encourage young men to undergo self-examination.

Key words: testicular cancer, self-examination of testicles

\section{Introduction}

Testicular cancer accounts for $1.6 \%$ of all malignant tumours among men [1]. However, in the age group between 20 and 44 , every fourth malignant tumour is testicular cancer. The risk of developing this disease peaks between the age 25 and 30 years old, with about $70 \%$ of cases occurring before the age of 40 [1-3]. The incidence rate is still increasing; among young adults it is the highest and in the last 40 years in Poland the incidence rate has skyrocketed with more than a 3-fold increase [4].

The objective of this study was to evaluate the level of awareness of the risk of testicular cancer among young men.

\section{Material and methods}

All male students from the University of Warmia and Mazury in Olsztyn were invited to take part in the study. The

\section{How to cite:}

Sugajska A, Dudkiewicz M, Szmit M, Jankowski R, Ciesak R, Wołyniec M, Feruś K, Bąk K, Kotlińska J, Wojciechowski P, Mesfer Almalki M, Bawazir BA, Wroński K, Osowiecka K, Rucińska M. Testicular cancer risk incidence in young men. NOWOTWORY J Oncol 2020; 70: 230-235. 
students anonymously filled out a paper or an electronic questionnaire.

\section{Statistical analysis}

In order to compare the proportions in specific subgroups, the chi test ${ }^{2}$ was performed. The significance level was adopted to be $p<0.05$. The analysis was performed with STATISTICA software (version 13,3; Statsoft; Poland).

\section{Results}

296 students, aged between 20 and 32 (median age: 23 years), of various departments of the University of Warmia and Mazury in Olsztyn took part in the study. The participants were divided into groups depending on their field of study:

- Humanities (78 students: 26\%),

- Mathematics (60 students: 20\%),

- Life Sciences (59 students: 20\%),

- Medical (99 students: 34\%, including 50 students of the English Language) (tab. I).

About two thirds of the students of Humanities, Mathematics and Life Sciences (64\%, 72\% and 77\% respondents respectively) had not previously been interested in the issue

Table I. The Characteristics of the study group

\begin{tabular}{|c|c|c|}
\hline Characteristics & $\begin{array}{c}N \\
296\end{array}$ & $\begin{array}{c}\% \\
100\end{array}$ \\
\hline \multicolumn{3}{|c|}{ Age: range: $20-32$ years, mean age $23, \pm 2.2$ years } \\
\hline \multicolumn{3}{|l|}{ Faculties } \\
\hline life sciences & 59 & 20.0 \\
\hline humanities & 78 & 26.3 \\
\hline mathematics & 60 & 20.3 \\
\hline medicine - Polish language faculty & 49 & 16.6 \\
\hline medicine - English language faculty & 50 & 16.9 \\
\hline \multicolumn{3}{|l|}{ Are you a religious person? } \\
\hline yes & 198 & 66.9 \\
\hline no & 98 & 33.1 \\
\hline \multicolumn{3}{|c|}{$\begin{array}{l}\text { Do you have a sexual relationship with } \\
\text { a woman? }\end{array}$} \\
\hline yes & 199 & 67.2 \\
\hline no & 97 & 32.8 \\
\hline \multicolumn{3}{|c|}{$\begin{array}{l}\text { Do you have a sexual relationship with } \\
\text { a man? }\end{array}$} \\
\hline yes & 16 & 5.4 \\
\hline no & 280 & 94.6 \\
\hline \multicolumn{3}{|c|}{ Does your partner touch your testicles? } \\
\hline yes & 117 & 39.5 \\
\hline no & 179 & 60.5 \\
\hline \multicolumn{3}{|c|}{$\begin{array}{l}\text { Has a member of your family or a friend ever suffered from } \\
\text { testicular cancer? }\end{array}$} \\
\hline yes & 22 & 7.4 \\
\hline no & 274 & 92.6 \\
\hline
\end{tabular}

\pm standard deviation of testicular cancer. The students of the Faculty of Medicine, however, knew about the subject - this was declared by more than a half of the respondents (61\% students of the Polish Language Faculty and 52\% of the English Language Faculty respectively). The students of Medicine were more often interested in the issue of testicular cancer than students of other faculties (57\% and $28 \%$ respectively; $p<0.001)$. People who knew somebody who had suffered from testicular cancer, often paid slightly more attention to this issue ( $p=0.09)$ (tab. II).

Fewer than $25 \%$ of surveyed students correctly pointed out the age when testicular cancer occurs most frequently, whilst the students of Medicine were more often able to point to the correct age group (48\% correct answers among the students of Medicine vs. $12 \%$ other students, $p<0.001)$.

The majority (68\%) declared that they did not know the risk factors of testicular cancer (this rate was the highest among the students of mathematics - 95\%). The persons who declared the knowledge of the risk factors, most frequently listed the environmental factors and those connected with the lifestyle (drinking alcohol and tobacco smoking). Nearly a half of the students of Medicine (45\%) knew the risk factors (57\% students of the Polish Language Faculty and 34\% of the English Language Faculty). A significant difference in this respect was observed between the students of the Faculty of Medicine and other faculties ( $p<0.001)$ (fig.1).

The question, "do you know the symptoms of testicular cancer?" was answered positively by $61 \%$ students of Medicine and only by $17 \%$ students of other faculties ( $p<0.001$ ). The students who declared that they knew the symptoms of testicular cancer mentioned mainly pain and enlargement/ oedema of the testicle (57\% respondents) as well as a tumour in the testicle (38\% respondents).

Only 29\% of all surveyed students declared that they perform testicular self-examinations - this rate was the lowest (15\%) among the students of Humanities, and the highest (47\%) among the Polish-language Medical students ( $p<0.001)$. Self-examination of testicles was more often performed by

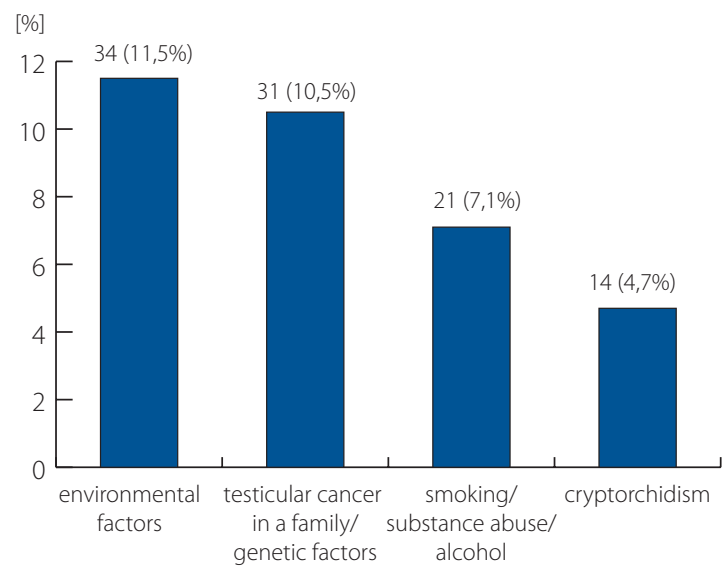

Figure 1. Factors affecting the development of testicular cancer as mentioned by the respondents 
men whose friends or family members had testicular cancer ( $p=0.02$ ) and those who declared that their sexual partners touch their testicles $(p=0.009)$. The majority of students who examine their testicles declared that they knew how to perform a self-examination (80\%) (tab. III).

The questionnaire showed that a definite majority of the surveyed students (91\%) were never informed by doctors about the risk of developing testicular cancer and the necessity of regular self-examination of testicles (tab. II). In general, more than a half of all the respondents (58\%) never looked for any information concerning testicular cancer ( for students of Humanities, Mathematics and Life Sciences this rate was 72\%). Such information was searched for by $73.5 \%$ of Polish-language students of Medicine and 52\% English-language students of

Table II. The factors which determine an increase of interest in the issue of testicular cancer and self-examination of testicles among young men

\begin{tabular}{|c|c|c|c|c|c|}
\hline \multicolumn{6}{|c|}{ Have you ever been curious to find out more about the issue of testicular cancer? } \\
\hline & \multicolumn{2}{|c|}{ yes } & \multicolumn{2}{|c|}{ no } & \multirow[b]{2}{*}{$\mathrm{p}$} \\
\hline & $\mathrm{N}$ & $\%$ & N & $\%$ & \\
\hline Total & 112 & 37.8 & 184 & 62.2 & \\
\hline \multicolumn{6}{|l|}{ Faculties } \\
\hline - life sciences & 21 & 35.6 & 38 & 64.4 & \multirow{5}{*}{$<0.001$} \\
\hline - humanities & 18 & 23.1 & 60 & 76.9 & \\
\hline - mathematics & 17 & 28.3 & 43 & 71.7 & \\
\hline - medicine - Polish language faculty & 30 & 61.2 & 19 & 38.8 & \\
\hline - medicine - English language faculty & 26 & 52.0 & 24 & 48.0 & \\
\hline \multicolumn{6}{|c|}{ Has a member of your family or a friend ever suffered from testicular cancer? } \\
\hline yes & 12 & 10.7 & 10 & 5.4 & \multirow{2}{*}{0.09} \\
\hline no & 100 & 89.3 & 174 & 94.6 & \\
\hline \multicolumn{6}{|c|}{ Do you have a sexual relationship with a woman? } \\
\hline yes & 80 & 71.4 & 119 & 64.7 & \multirow{2}{*}{0.23} \\
\hline no & 32 & 28.6 & 65 & 35.3 & \\
\hline \multicolumn{6}{|c|}{ Do you have a sexual relationship with a man? } \\
\hline yes & 7 & 6.3 & 9 & 4.9 & \multirow{2}{*}{0.62} \\
\hline no & 105 & 93.7 & 175 & 95.1 & \\
\hline \multicolumn{6}{|l|}{ Does your partner touch your testicles? } \\
\hline yes & 47 & 42.0 & 70 & 38.0 & \multirow{2}{*}{0.50} \\
\hline no & 65 & 58.0 & 114 & 62.0 & \\
\hline \multicolumn{6}{|l|}{ Are you a religious person? } \\
\hline yes & 82 & 73.2 & 116 & 63.0 & \multirow{2}{*}{0.07} \\
\hline no & 30 & 26.8 & 68 & 37.0 & \\
\hline
\end{tabular}

Table III. The factors which determine an interest in self-examination of testicles among young men

\begin{tabular}{|c|c|c|c|c|c|}
\hline \multicolumn{6}{|c|}{ Do you perform self-examination of the testicles? } \\
\hline & \multicolumn{2}{|c|}{ yes } & \multicolumn{2}{|c|}{ no } & \multirow[b]{2}{*}{$p$} \\
\hline & N & $\%$ & N & $\%$ & \\
\hline Total & 86 & 29.1 & 210 & 70.9 & \\
\hline \multicolumn{6}{|l|}{ Faculties } \\
\hline - life sciences & 16 & 27 & 43 & 73 & \multirow{5}{*}{$<0.001$} \\
\hline - humanities & 12 & 15 & 66 & 85 & \\
\hline - mathematics & 11 & 18 & 49 & 82 & \\
\hline - medicine - Polish language faculty & 23 & 47 & 26 & 53 & \\
\hline - medicine - English language faculty & 18 & 36 & 32 & 64 & \\
\hline
\end{tabular}




\begin{tabular}{|c|c|c|c|c|c|}
\hline \multicolumn{6}{|c|}{$\begin{array}{l}\text { Has a member of your family or a friend ever suffered from testicular } \\
\text { cancer? }\end{array}$} \\
\hline yes & 11 & 12,8 & 11 & 5.2 & \multirow{2}{*}{0.02} \\
\hline no & 75 & 87.2 & 199 & 94.8 & \\
\hline \multicolumn{6}{|c|}{ Do you have a sexual relationship with a woman? } \\
\hline yes & 61 & 70.9 & 138 & 65.7 & \multirow{2}{*}{0.39} \\
\hline no & 25 & 29.1 & 72 & 34.3 & \\
\hline \multicolumn{6}{|c|}{ Do you have a sexual relationship with a man? } \\
\hline yes & 8 & 9.3 & 8 & 3.8 & \multirow{2}{*}{0.06} \\
\hline no & 78 & 90.7 & 202 & 96.2 & \\
\hline \multicolumn{6}{|c|}{ Does your partner touch your testicles? } \\
\hline yes & 44 & 51.2 & 73 & 34.8 & \multirow{2}{*}{0.009} \\
\hline no & 42 & 48.8 & 137 & 65.2 & \\
\hline \multicolumn{6}{|c|}{ Are you a religious person? } \\
\hline yes & 56 & 65.1 & 142 & 67.6 & \multirow{2}{*}{0.68} \\
\hline no & 30 & 34.9 & 68 & 32.4 & \\
\hline \multicolumn{6}{|c|}{ Do you know about the technique of self-examination of the testicles and do you know how to carry out such an examination? } \\
\hline yes & 69 & 80.2 & 24 & 11.4 & \multirow{2}{*}{$<0.001$} \\
\hline no & 17 & 19.8 & 186 & 88.6 & \\
\hline
\end{tabular}

Medicine. These students of Medicine looked for information concerning testicular cancer twice as often as students of other faculties ( 63 and $31 \%$ respectively; $p<0.001$ ). They pointed to the Internet as the main source of information, mentioning doctors quite rarely as a source (7\%) - the same with medical journals and educational materials (9\%). University classes were a source of knowledge for $40 \%$ of students of Medicine and for $3 \%$ of students from other faculties (tab. IV).

\section{Discussion}

Knowledge concerning testicular cancer among adolescents and young men is insufficient: for example young men from Northern Ireland were unable to define the age when testicular cancer occurs; additionally, they did not know the risk factors or the main symptoms of the disease. The respondents considered obesity and excessive alcohol consumption to be the main risk factors [5]. Similar responses were provided by surveyed students of the University of Warmia and Mazury in Olsztyn.

Undescended testes, even if they dropped to the scrotum during childhood, as well as the presence of testicular cancer in a father or a brother are risk factors in the development of testicular cancer [6], yet only $5 \%$ of the surveyed subjects regarded cryptorchidism as a risk factor, with only $10 \%$ of students pointing to genetic factors. Fewer than $25 \%$ of respondents were able to point to the age when testicular cancer occurs most frequently, whilst this rate was lowered down to $13 \%$ once medical students were excluded from the group. This rate was similar to the study performed by Khadra et al. (26\%) [7].

So far the usefulness of the screening tests for early detection of testicular cancer has not been proven [8-10]. Moreover, there appears no effect regarding self-examination of the testicles on the reduction of disease mortality [8]. The reason for the lack of such an effect may be the very good prognosis, even in more advanced stages of the disease. In spite of this, the European Association of Urology recommends periodical self-examination of the testicles [10], and the American Cancer Society recommends testicle self-examination for males with an increased risk of developing the disease [11]. However, for young men to be willing to self-examine, awareness of the risk and a knowledge of the disease's symptoms is necessary. Young men do not know about the early symptoms of testicular cancer $[5,12]$. As many as 58\% of respondents in the analysis performed by Ugwumba et al. [13] pointed to a pain in a testicle as a symptom of this disease. The students of the University of Warmia and Mazury provided similar answers: $57 \%$ of respondents who claimed to know the symptoms of testicular cancer, pointed to pain as the disease symptom. The fact that an increase in the size of a testicle or a testicular tumour might be a sign of testicular cancer was known to only $19 \%$ and $12 \%$ of all surveyed students respectively.

A few studies carried out in the 80 s and 90 s among American students showed that only $25-61 \%$ had heard something about testicular cancer and fewer than 20\% examined their own testicles [14]. Similarly as in Europe, $87 \%$ of students out of more 
Table IV. Sources of information concerning testicular cancer

\begin{tabular}{|c|c|c|c|c|c|c|c|c|c|c|}
\hline \multirow[t]{2}{*}{ faculties } & \multicolumn{2}{|c|}{ life sciences } & \multicolumn{2}{|c|}{ humanities } & \multicolumn{2}{|c|}{ mathematics } & \multicolumn{2}{|c|}{$\begin{array}{c}\text { medicine } \\
\text { - Polish } \\
\text { language faculty }\end{array}$} & \multicolumn{2}{|c|}{$\begin{array}{c}\text { medicine } \\
\text { - English } \\
\text { language faculty }\end{array}$} \\
\hline & $\mathbf{N}$ & $\%$ & $\mathbf{N}$ & $\%$ & $\mathbf{N}$ & $\%$ & $\mathbf{N}$ & $\%$ & $\mathbf{N}$ & $\%$ \\
\hline I never look for such information & 35 & 59.3 & 55 & 70.5 & 45 & 79.0 & 13 & 26.5 & 24 & 48.0 \\
\hline I look for this information & 24 & 40.7 & 23 & 29.5 & 15 & 21.0 & 36 & 73.5 & 26 & 52.0 \\
\hline radio / television / press & 1 & 4.2 & 4 & 17.4 & 1 & 6.7 & 1 & 2.8 & 2 & 7.7 \\
\hline internet & 22 & 91.7 & 22 & 95.6 & 15 & 100.0 & 24 & 66.7 & 16 & 61.5 \\
\hline family & 0 & 0.0 & 0 & 0.0 & 0 & 0.0 & 2 & 5.6 & 3 & 11.5 \\
\hline friends & 0 & 0.0 & 3 & 13.0 & 1 & 6.7 & 2 & 5.6 & 3 & 11.5 \\
\hline school / university & 2 & 8.4 & 0 & 0.0 & 0 & 0.0 & 15 & 41.7 & 10 & 38.5 \\
\hline family doctor / GP & 0 & 0.0 & 4 & 17.4 & 3 & 20.0 & 5 & 13.9 & 1 & 3.8 \\
\hline other doctors / specialists & 0 & 0.0 & 3 & 13.0 & 1 & 6.7 & 3 & 8.3 & 1 & 3.8 \\
\hline medical press / medical leaflets & 4 & 16.8 & 6 & 26.1 & 1 & 6.7 & 13 & 36.1 & 3 & 11.5 \\
\hline
\end{tabular}

than 7000 respondents from 20 countries never performed self-examination of the testicles $[14,15]$. Some later research showed that more young men knew about testicular cancer, yet still very few of them performed self-examination $[5,16,17]$. In 1999-2001, out of 8000 students from 13 European countries, only $18.2 \%$ of them performed self-examination of the testicles [17]. The largest rate of students who self-examined their testicles was in Great Britain (36.3\%) and Ireland (34.8\%). In Poland, in a group of 359 surveyed students, 16.7\% of them declared to perform testicular self-examinations [17]. The study carried out by Peltzer et al. covering more than 2000 students from African countries showed that testicles were examined by only $13.6 \%$ of these young men [18]. In the group of students from the University of Warmia and Mazury, 29\% of the surveyed men declared that they self-examine their testicles at least once a year, but only half of them make the self-examination once a month.

A British study comprising 1000 patients of a urology outpatient clinic/urology ward, found that as many as $86 \%$ of men had never performed a self-examination of the testicles with $15 \%$ of them receiving the information about this examination from family doctors while 9\% of them learning about it at schools [19]. In the study of Khadra et al. [7], only $16 \%$ of men who perform self-examination of the testicles were instructed by the family doctor or a nurse, and $56 \%$ of them gained the information from the media. More than half of the surveyed people believed that testicular self-examinations should be taught at school (60\% of respondents) and by family doctors (55\% of respondents) [19]. Young men themselves, however, are not inclined to take up the subject of testicular cancer with a doctor [5]. In the United States, it is recommended that family doctors provide information about testicular cancer and teach men between the age of 15-35 to self-examine their testicles [20]. It has been proven that men who have more knowledge about testicular cancer, perform self-examinations of their testicles more frequently than others $[5,10,16]$. It was also observed that those who talked with their GP about testicular cancer and were instructed how to perform self-examinations, contacted a specialist sooner and more frequently once they observed any abnormalities in their testicles [21]. Among the students of the University of Warmia and Mazury, $91 \%$ of the surveyed subjects claimed that a doctor never informed them about the risk of testicular cancer and never encouraged them to undergo self-examination.

\section{Conclusions}

Young men do not have any knowledge about the symptoms of testicular cancer, rarely perform self-examination of the testicles and are not informed by their GPs about the necessity to perform self-examinations. Therefore, knowledge about testicular cancer should be disseminated among young men (for example in school or university classes) and they should be encouraged to perform self-examinations.

Conflict of interest: none declared

\author{
Monika Rucińska \\ University of Warmia and Mazury in Olsztyn \\ Collegium Medicum \\ Department of Oncology, Faculty of Medicine \\ al. Wojska Polskiego 37 \\ 10-228 Olsztyn, Poland \\ e-mail:m_rucinska@poczta.onet.pl
}

Received: 13 May 2020

Accepted: $31 \mathrm{Jul} 2020$

\section{References}

1. https://seer.cancer.gov/statfacts/html/testis.html.

2. Huyghe E, Matsuda T, Thonneau P. Increasing incidence of testicular cancer worldwide: a review. J Urol. 2003; 170(1): 5-11, doi: 10.1097/01. ju.0000053866.68623.da, indexed in Pubmed: 12796635. 
3. Shanmugalingam T, Soultati A, Chowdhury $S$, et al. Global incidence and outcome of testicular cancer. Clin Epidemiol. 2013; 5: 417-427, doi: 10.2147/CLEP.S34430, indexed in Pubmed: 24204171.

4. http://onkologia.org.pl/.

5. Roy RK, Casson K. Attitudes Toward Testicular Cancer and Self-Examination Among Northern Irish Males. Am J Mens Health. 2017; 11(2): $253-$ 261, doi: 10.1177/1557988316668131, indexed in Pubmed: 27645516.

6. Turnbull C, Rahman N. Genome-wide association studies provide new insights into the genetic basis of testicular germ-cell tumour. Int J Androl. 2011; 34(4 Pt 2): e86-96; discussion e96, doi: 10.1111/j.1365-2605.2011.01162.x, indexed in Pubmed: 21623831.

7. Khadra A, Oakeshott P. Pilot study of testicular cancer awareness and testicular self-examination in men attending two South London general practices. Fam Pract. 2002; 19(3): 294-296, doi: 10.1093/fampra/19.3.294, indexed in Pubmed: 11978722.

8. Ilic D, Misso ML. Screening for testicular cancer. Cochrane Database Syst Rev. 2011(2): CD007853, doi: 10.1002/14651858.CD007853.pub2, indexed in Pubmed: 21328302.

9. Lin K, Sharangpani R. Screening for testicular cancer: an evidence review for the U.S. Preventive Services Task Force. Ann Intern Med. 2010; 153(6): 396-399, doi: 10.7326/0003-4819-153-6-201009210-00007, indexed in Pubmed: 20855803.

10. Saab MM, Landers M, Hegarty J, et al. Testicular Cancer Awareness and Screening Practices: A Systematic Review. Oncol Nurs Forum. 2016; 43(1): E8-23, doi: 10.1188/16.ONF.E8-E23, indexed in Pubmed: 26679456.

11. Albers $\mathrm{P}$, Albrecht W, Algaba F, et al. European Association of Urology. Guidelines on Testicular Cancer: 2015 Update. Eur Urol. 2015; 68(6): 1054-1068, doi: 10.1016/j.eururo.2015.07.044, indexed in Pubmed: 26297604.

12. https://www.cancer.org/cancer/testicular-cancer/detection-diagnosis-staging/detection.html.

13. Ugwumba FO, Ekwueme OE, Okoh AD. Testicular Cancer and Testicular Self-Examination; Knowledge, Attitudes and Practice in Final Year
Medical Students in Nigeria. Asian Pac J Cancer Prev. 2016; 17(11): 4999-5003, doi: 10.22034/APJCP.2016.17.11.4999, indexed in Pubmed: 28032730.

14. Ward KD, Vander Weg MW, Read MC, et al. Testicular cancer awareness and self-examination among adolescent males in a community-based youth organization. Prev Med. 2005; 41(2): 386-398, doi: 10.1016/j. ypmed.2005.02.003, indexed in Pubmed: 15917035.

15. Wardle J, Steptoe A, Burckhardt R, et al. Testicular self-examination: attitudes and practices among young men in Europe. Prev Med. 1994; 23(2): 206-210, doi: 10.1006/pmed.1994.1028, indexed in Pubmed: 8047527.

16. Umeh K, Chadwick R. Early detection of testicular cancer: revisiting the role of self-efficacy in testicular self-examination among young asymptomatic males. J Behav Med. 2016; 39(1): 151-160, doi: 10.1007/ s10865-010-9262-z, indexed in Pubmed: 20411318.

17. Evans R, Steptoe A, Wardle J. Testicular self-examination: change in rates of practice in European university students, from 13 countries, over a 10-year period. The Journal of Men's Health \& Gender. 2006; 3(4): 368-372, doi: 10.1016/j.jmhg.2006.08.005.

18. Peltzer K, Pengpid S. Knowledge, Attitudes and Practice of Testicular Self- examination among Male University Students from Bangladesh, Madagascar, Singapore, South Africa and Turkey. Asian Pac J Cancer Prev. 2015; 16(11): 4741-4743, doi: 10.7314/apjcp.2015.16.11.4741, indexed in Pubmed: 26107234.

19. Handy P, Sankar K. Testicular self examination - Knowledge of men attending a large Genito Urinary Medicine clinic. Health Education Journal. 2008; 67(1): 9-15, doi: 10.1177/0017896907083152.

20. Green M, Palfrey JS. editors. Bright futures: guidelines for health supervision of infants, children, and adolescents, 2nd ed. Rev. Arlington (VA)'National Center for Education in Maternal and Child Health 2002.

21. Cronholm PF, Mao JJ, Nguyen GT, et al. A dilemma in male engagement in preventive services: adolescent males' knowledge and attitudes toward testicular cancer and testicular self-exam. Am J Mens Health. 2009; 3(2): 134-140, doi: 10.1177/1557988308315071, indexed in Pubmed: 19477726. 